\title{
Erratum
}

\section{Erratum to: IMPACT OF NATURAL GAS FUEL CHARACTERISTICS ON THE DESIGN AND COMBUSTION PERFORMANCE OF A NEW LIGHT-DUTY CNG ENGINE}

\author{
Zhiyu Han ${ }^{1)}$, Zhenkuo $\mathrm{Wu}^{1)^{*}}$, Yongcheng Huang ${ }^{2)}$, Yongsheng Shi ${ }^{3)}$ and Wei Liu ${ }^{3)}$ \\ ${ }^{1)}$ Postdotoral Station of Mechanical Engineering, School of Automotive Studies, \\ Tongji University, Shanghai 201804, China \\ ${ }^{2)}$ School of Energy and Power Engineering, Xi' an Jiaotong University, Xi'an 710049, China \\ ${ }^{3)}$ Smapow Engine Company, 12 North Honghai Road, Huai'an, Jiangsu 223001, China
}

Erratum to: International Journal of Automotive Technology, Vol. 22, No. 6, pp. 1619-1631 (2021)

DOI 10.1007/s12239-021-0140-1

The page number of the above article should be as follows:

pp. 1619-1630 